\title{
Cardiac Magnetic Resonance in pregnant women: supine or left lateral position?
}

\author{
Alexia Rossi*, Jerome Cornette, Tirza Springeling, Petra Opic, \\ Chen Chia Hui, Adriaan Moelker, Gabriel P Krestin, Eric Steegers, \\ Jolien Roos-Hesselink, Jolien Roos-Hesselink and Robert Jan van Geuns
}

Address: Erasmus MC, Rotterdam, Netherlands

* Corresponding author

from 13th Annual SCMR Scientific Sessions

Phoenix, AZ, USA. 21 -24 January 2010

Published: 21 January 2010

Journal of Cardiovascular Magnetic Resonance 2010, I2(SuppI I):PI 24 doi:I0.I I86/I532-429X-I2-SI-PI 24

This abstract is available from: http://jcmr-online.com/content/I2/SI/PI24

(c) 2010 Rossi et al; licensee BioMed Central Ltd.

\section{Introduction}

Postural changes can affect cardiac functional parameters in normal pregnancy.

\section{Purpose}

The purpose of our study was to evaluate the cardiovascular response to postural changes during pregnancy at 20 and 32 weeks gestation.

\section{Methods}

Fourteen healthy pregnant women with a mean (SD) age 30.3 (5.2) years were studied with cardiac MR (CMR) in supine position and after 30 minutes in left lateral (LL) position. Six/14 were in the 20th week gestation; 8/14 were in the 32nd week pregnancy. Heart rate (HR), ejection fraction (EF), end-diastolic volume (EDV), end-systolic volume (ESV), stroke volume (SV) and cardiac output (CO) were compared in both positions. Lateral and supero-inferior left atrial (LA) diameters were measured at the end systole on a four chamber view in both postures.

\section{Results}

During supine position HR was $80 \pm 13$ bpm vs. $73 \pm 9$ bpm in the LL position (p-value $=0.07$ ). The EF, EDV, SV and $\mathrm{CO}$ increased significantly during LL position $(10.71 \%, 18.76 \%, 29.21 \%$ and $18.04 \%$ respectively, pvalue $<0.05)$ at 20 and 32 weeks. No significant changes occurred in ESV between supine and LL positions (65.3 \pm 16.37 vs. $69.3 \pm 18.1 \mathrm{ml}$, p-value > 0.05). Lateral LA diam- eter did not vary significantly $(35.0 \pm 2.9$ vs. $39.6 \pm 3.6 \mathrm{ml}$, $\mathrm{p}=0.05$ ) but supero-inferior LA diameter increased from a mean value of $40.1 \pm 5.0$ in the supine position to 46.2 $\pm 4.8 \mathrm{~mm}$ in LL position, $\mathrm{p}$-value $=0.003$.

\section{Conclusion}

In normal pregnant women a change from supine to lateral position has been shown to increase EF, EDV, SV and $\mathrm{CO}$ without increase of ESV. This pattern is seen already at 20 weeks gestation, suggesting a diminished preload due to caval vein compression. 